\title{
Original
}

\section{Periodontitis modifies the association between smoking and chronic obstructive pulmonary disease in Japanese men}

\author{
Jane Harland1), Michiko Furuta1), Kenji Takeuchi²), Shunichi Tanaka), \\ and Yoshihisa Yamashita2)
}

\author{
1)Department of Dental Education, Kyushu University Faculty of Dental Science, Fukuoka, Japan \\ 2)Section of Preventive and Public Health Dentistry, Division of Oral Health, Growth and Development, \\ Kyushu University Faculty of Dental Science, Fukuoka, Japan \\ 3) Japanese Red Cross Kumamoto Healthcare Center, Kumamoto, Japan
}

(Received June 14, 2017; Accepted August 18, 2017)

\begin{abstract}
Periodontitis was reported to be associated with chronic obstructive pulmonary disease (COPD), and both diseases are related to smoking. To identify associations between periodontitis, smoking, and COPD, this cross-sectional study enrolled 1474 Japanese men (mean age $55.2 \pm 8.9$ years) surveyed between 2003 and 2006. Periodontal status was evaluated by using the community periodontal index. Periodontitis was defined as the presence of at least one sextant with a pocket depth $\geq 4 \mathrm{~mm}$. Lung function was measured by spirometry, and COPD was defined as ratio of forced expiratory volume after 1 second to forced vital capacity of $<\mathbf{0 . 7 0}$. Logistic regression analysis showed that the association between COPD and smoking was stronger for men with periodontitis (odds ratio 2.45 ; $95 \%$ confidence interval 1.37-4.37) than for those without periodontitis (odds ratio 1.64; 95\% confidence interval 0.91-2.94), after adjusting for age, number of present teeth, body mass index, alcohol intake, occupation, hypertension, and diabetes. The association between smoking and COPD was significant for men with periodontitis but was weaker for those without periodontitis. These findings suggest that periodontitis modifies the association between smoking and COPD.
\end{abstract}

Correspondence to Dr. Yoshihisa Yamashita, Section of Preventive and Public Health Dentistry, Division of Oral Health, Growth and Development, Kyushu University Faculty of Dental Science, 3-1-1 Maidashi, Higashi-ku, Fukuoka 812-8582, Japan Fax:+81-92-642-6354 E-mail: yoshi@dent.kyushu-u.ac.jp

doi.org/10.2334/josnusd.17-0225

DN/JST.JSTAGE/josnusd/17-0225
Keywords: periodontitis; pulmonary disease; chronic obstructive; smoking.

\section{Introduction}

Chronic obstructive pulmonary disease (COPD) is characterized by progressive airflow obstruction and airway inflammation. The prevalence of COPD is $9 \%$ to $10 \%$ in adults aged 40 years or older, but this estimate is mainly based on data from North America and Europe $(1,2)$. A 2004 Japanese study of adults aged 40 years or older reported a prevalence of $10.9 \%$ (3). The World Health Organization estimates that COPD is the fourth leading cause of death in the world and will be the third leading cause of death by $2030(4,5)$. COPD is considered a preventable and treatable cause of morbidity and mortality (6). Thus, it is important to improve our understanding of factors associated with COPD.

Several studies have noted a link between COPD and periodontitis (7-9). In addition, a recent meta-analysis reported a significant association between periodontitis and COPD but found evidence of publication bias (10). Smoking is an important risk factor for periodontitis (11-14) and the most important causative factor in COPD development $(15,16)$. Previous studies found an association between COPD and periodontitis in current smokers but not in former or never-smokers $(8,17-19)$. Therefore, it appears that the combination of periodontitis and smoking plays a role in COPD development. However, the interactive effect of periodontitis and smoking on COPD has not been clarified. We examined the associations of periodontitis and smoking with COPD in 
Japanese men.

\section{Study participants \\ Materials and Methods}

This cross-sectional study analyzed dental and medical data from health check-ups at the Japanese Red Cross Kumamoto Healthcare Center, in Kumamoto, Japan. We analyzed available records for 1795 men for the period from 2003 through 2006 (344 men in 2003, 711 in 2004, 580 in 2005, and 160 men in 2006). We excluded 44 men with fewer than 10 teeth, 34 with a history of lung disease (asthma, emphysema, or chronic bronchitis), and 243 men with missing data. Ultimately, data from 1474 men (mean age $55.2 \pm 8.9$ years) were analyzed. This study was approved by the Kyushu University Institutional Review Board for Clinical Research (No. 22-71).

\section{Dental and medical examination and questionnaire}

The participants' oral health status was assessed by a dentist (ST) in 2003, 2004, 2005, and 2006. To determine oral health status, the number of teeth was recorded, and periodontal condition was assessed in all present teeth. Periodontal status was evaluated by using the Community Periodontal Index (CPI) (20), and the highest CPI code for each sextant was recorded and analyzed. Periodontitis was defined as the presence of at least one sextant with a pocket depth $\geq 4 \mathrm{~mm}$ (CPI score $\geq 3$ ).

COPD was assessed with spirometry and defined as a ratio of forced expiratory volume after 1 second to forced vital capacity of $<0.70$, as suggested by the Global Initiative for Chronic Obstructive Lung Disease (GOLD) classification for airflow limitation (Global Strategy for the Diagnosis, Management and Prevention of COPD, GOLD 2016; http://goldcopd.org/).

Weight and height data were used to calculate body mass index (BMI). Underweight was defined as a BMI less than 18.5 , normal weight as a BMI between 18.5 and 24.9 , and overweight as a BMI of 25.0 or higher. Information on smoking status, alcohol consumption, drug therapy for hypertension and diabetes, and occupational status was obtained from a self-administered questionnaire. Participants were categorized as never-smokers (men who had never smoked regularly) and former/ current smokers. The cumulative dose of smoking was expressed in pack-years. One pack-year is equivalent to 20 cigarettes smoked per day for 1 year. Alcohol consumption was classified by frequency as never drinking, drinking 1 to 4 days a week, and drinking more than 4 days a week. Occupational status was divided into four categories: professional or manager, office worker, other worker, and homemaker, unemployed, or retired.
"Other worker" includes skilled workers, salespeople, service workers, security guards, farmers, fishers, transport workers, and telecommunications workers.

\section{Statistical analysis}

To evaluate associations between COPD, periodontitis, and COPD-related factors, the chi-square test was used to analyze categorical variables and the Mann-Whitney $U$ test was used for continuous variables. To explore the combined association of periodontitis and smoking with COPD, participants were classified into four groups, namely, no periodontitis and no smoking, periodontitis and no smoking, no periodontitis and smoking, and periodontitis and smoking. Logistic regression was used to examine the multivariate association of COPD (dependent variable) with periodontitis and smoking (independent variables) and to calculate odds ratios (ORs) and $95 \%$ confidence intervals (CIs). The following logistic regression models were tested: 1) a model including periodontitis and smoking, 2) a model including smoking, stratified by periodontitis status, and 3) a model including the combination of periodontitis and smoking. Smoking status and pack-years of cigarette smoking were entered separately into the model including smoking status and the model including pack-years of cigarette smoking. In the logistic regression model for presence of COPD, the potential confounders were age, number of present teeth, BMI, alcohol consumption, occupation, hypertension, and diabetes. SPSS software (version 23.0 for Macintosh; IBM Japan, Tokyo, Japan) was used for data analysis, and a $P$ value less than 0.05 (two-sided) was considered to indicate statistical significance.

\section{Results}

The demographic and clinical characteristics of participants with COPD $(n=149)$ and without $\operatorname{COPD}(n=1325)$ are shown in Table 1. The percentages of participants with a highest CPI score of $0,1,2,3$, or 4 were $14.7 \%, 12.2 \%$, $25.4 \%, 45.9 \%$, and $1.8 \%$, respectively. COPD prevalence was $12.7 \%$ among participants with periodontitis and $7.8 \%$ among participants without periodontitis. Table 1 shows that age, number of present teeth, presence of periodontal disease, history of smoking, BMI, and occupational status significantly differed between men with and without COPD.

Logistic regression analysis showed that smoking status and pack-years of cigarette smoking were significantly associated with COPD, after adjusting for age, number of present teeth, BMI, alcohol consumption, occupation, and medical treatment of hypertension and diabetes (Table 2). However, the association between 
Table 1 Demographic and clinical characteristics of study participants, by COPD status

\begin{tabular}{|c|c|c|c|c|}
\hline & $\begin{array}{l}\text { No COPD } \\
(n=1325)\end{array}$ & $\begin{array}{c}\text { COPD } \\
(n=149)\end{array}$ & $\begin{array}{c}\text { All } \\
(n=1474)\end{array}$ & $P$ value \\
\hline Age & $54.5 \pm 8.7$ & $61.3 \pm 9.1$ & $55.2 \pm 8.9$ & $<0.001^{*}$ \\
\hline Number of present teeth & $26.5 \pm 3.8$ & $25.2 \pm 4.9$ & $26.4 \pm 3.9$ & $0.002 *$ \\
\hline Periodontal disease & & & & $0.002^{\dagger}$ \\
\hline No & $711(92.2)$ & $60(7.8)$ & 771 & \\
\hline Yes & $614(87.3)$ & $89(12.7)$ & 703 & \\
\hline Smoking status & & & & $0.025^{\dagger}$ \\
\hline Never-smoker & $478(92.3)$ & $40(7.7)$ & 518 & \\
\hline Former/current smoker & $847(88.6)$ & $109(11.4)$ & 956 & \\
\hline Pack-years of cigarette smoking & $17.8 \pm 20.1$ & $25.8 \pm 24.4$ & $18.6 \pm 20.7$ & $<0.001^{*}$ \\
\hline Periodontitis and smoking status & & & & $0.003^{\dagger}$ \\
\hline Periodontitis $(-)$, smoker $(-)$ & $287(93.5)$ & $20(6.5)$ & 307 & \\
\hline Periodontitis $(+)$, smoker $(-)$ & $191(90.5)$ & $20(9.5)$ & 211 & \\
\hline Periodontitis $(-)$, smoker $(+)$ & $424(91.4)$ & $40(8.6)$ & 464 & \\
\hline Periodontitis $(+)$, smoker $(+)$ & $423(86.0)$ & $69(14.0)$ & 492 & \\
\hline BMI & & & & $<0.001^{\dagger}$ \\
\hline Underweight/normal & $908(88.0)$ & $124(12.0)$ & 1032 & \\
\hline Overweight & $417(94.3)$ & $25(5.7)$ & 442 & \\
\hline Drinking frequency & & & & $0.065^{\dagger}$ \\
\hline Never & $296(89.2)$ & $36(10.8)$ & 332 & \\
\hline 1-4 days/week & $347(93.0)$ & $26(7.0)$ & 373 & \\
\hline$>4$ days/week & $682(88.7)$ & $87(11.3)$ & 769 & \\
\hline Occupational status & & & & $<0.001^{\dagger}$ \\
\hline Professional/manager & $446(91.0)$ & $44(9.0)$ & 490 & \\
\hline Office worker & $410(94.0)$ & $26(6.0)$ & 436 & \\
\hline Other worker & $273(91.0)$ & $27(9.0)$ & 300 & \\
\hline Homemaker/unemployed/retired & $196(79.0)$ & $52(21.0)$ & 248 & \\
\hline Hypertension & & & & $0.282^{\dagger}$ \\
\hline No & $1129(90.2)$ & $122(9.8)$ & 1251 & \\
\hline Yes & $196(87.9)$ & $27(12.1)$ & 223 & \\
\hline Diabetes & & & & $0.678^{\dagger}$ \\
\hline No & $1281(89.8)$ & $145(10.2)$ & 1426 & \\
\hline Yes & $44(91.7)$ & $4(8.3)$ & 48 & \\
\hline
\end{tabular}

periodontitis and COPD was not statistically significant.

Regression analyses stratified by periodontitis status showed that the association between smoking status and COPD was stronger for men with periodontitis (OR 2.45; $95 \%$ confidence interval $1.37-4.37$ ) than for those without periodontitis (OR 1.64; 95\% confidence interval 0.91-2.94) (Table 3). The association was similar for pack-years of cigarette smoking. In analysis stratified by smoking status, no significant association between periodontitis and COPD was observed among smokers or never-smokers.

When ever-smokers with periodontitis were compared with never-smokers without periodontitis, the combined presence of periodontitis and smoking was significantly associated with COPD (OR 2.27; 95\% confidence interval 1.31-3.92) (Table 4).

\section{Discussion}

The main finding of this cross-sectional study was that COPD risk was higher for Japanese male smokers with periodontitis than for those without periodontitis. This finding sheds light on the associations between periodontitis, smoking, and COPD.

The present study expands on previous research by showing that periodontitis modifies the association between smoking and COPD. A separate analysis of periodontitis revealed a significant association between smoking and COPD in men with periodontitis. Even in men without periodontitis, smoking tended to be associated with COPD, although the association was not significant. The adjusted OR for COPD among ever-smokers was 2.5 in men with periodontitis and 1.6 in men without periodontitis (Table 3), which suggests that the strength of the association between smoking and COPD is greater for men with periodontitis than for those without periodontitis. Thus, it is possible that periodontitis strengthens the association between smoking and COPD.

In contrast to earlier findings (7-10,21), we found that periodontitis was not significantly associated with 
Table 2 Odds ratios of periodontitis for COPD

\begin{tabular}{|c|c|c|c|c|}
\hline & \multicolumn{2}{|c|}{ Model 1} & \multicolumn{2}{|c|}{ Model 2} \\
\hline & $\begin{array}{l}\text { Adjusted OR } \\
(95 \% \mathrm{CI})\end{array}$ & $P$ value & $\begin{array}{c}\text { Adjusted OR } \\
(95 \% \mathrm{CI})\end{array}$ & $P$ value \\
\hline \multicolumn{5}{|l|}{ Periodontitis } \\
\hline No & 1.00 & & 1.00 & \\
\hline Yes & $1.23(0.85-1.78)$ & 0.280 & $1.16(0.80-1.69)$ & 0.430 \\
\hline \multicolumn{5}{|l|}{ Smoking status } \\
\hline Never-smoker & 1.00 & & & \\
\hline Former/current smoker & $2.00(1.33-3.00)$ & 0.001 & & \\
\hline Pack-years of cigarette smoking & & & $1.02(1.01-1.02)$ & $<0.001$ \\
\hline Age & $1.08(1.06-1.11)$ & $<0.001$ & $1.08(1.05-1.11)$ & $<0.001$ \\
\hline Number of present teeth & $0.97(0.93-1.02)$ & 0.202 & $0.98(0.94-1.02)$ & 0.978 \\
\hline \multicolumn{5}{|l|}{ BMI } \\
\hline Underweight/normal & 1.00 & & 1.00 & \\
\hline Overweight & $0.48(0.31-0.78)$ & 0.002 & $0.45(0.28-0.73)$ & 0.001 \\
\hline \multicolumn{5}{|l|}{ Drinking frequency } \\
\hline Never & 1.00 & & 1.00 & \\
\hline 1-4 days/week & $0.73(0.42-1.26)$ & 0.253 & $0.77(0.44-1.34)$ & 0.768 \\
\hline$>4$ days/week & $1.03(0.67-1.60)$ & 0.883 & $1.05(0.68-1.63)$ & 0.831 \\
\hline \multicolumn{5}{|l|}{ Occupational status } \\
\hline Professional/manager & 1.00 & & 1.00 & \\
\hline Office worker & $1.13(0.65-1.97)$ & 0.664 & $1.18(0.67-2.06)$ & 0.565 \\
\hline Other worker & $1.06(0.62-1.76)$ & 0.870 & $1.03(0.61-1.73)$ & 0.927 \\
\hline Homemaker/unemployed/retired & $1.15(0.69-1.92)$ & 0.595 & $1.11(0.66-1.86)$ & 0.690 \\
\hline \multicolumn{5}{|l|}{ Hypertension } \\
\hline No & 1.00 & & 1.00 & \\
\hline Yes & $0.97(0.60-1.56)$ & 0.884 & $0.96(0.59-1.56)$ & 0.871 \\
\hline \multicolumn{5}{|l|}{ Diabetes } \\
\hline No & 1.00 & & 1.00 & \\
\hline Yes & $0.60(0.20-1.78)$ & 0.360 & $0.54(0.18-1.66)$ & 0.282 \\
\hline
\end{tabular}

Models 1 and 2 included smoking status and pack-years of cigarette smoking, respectively.

COPD, chronic obstructive pulmonary disease; BMI, body mass index; OR, odds ratio; CI, confidence interval.

Table 3 Odds ratios (ORs) for the association between smoking and COPD, stratified by periodontitis status

\begin{tabular}{|c|c|c|c|c|}
\hline & \multicolumn{2}{|c|}{ Model 1} & \multicolumn{2}{|c|}{ Model 2} \\
\hline & $\begin{array}{c}\text { Adjusted OR } \\
(95 \% \mathrm{CI})\end{array}$ & $P$ value & $\begin{array}{c}\text { Adjusted OR } \\
(95 \% \mathrm{CI})\end{array}$ & $P$ value \\
\hline \multicolumn{5}{|l|}{ Periodontitis (-) } \\
\hline \multicolumn{5}{|l|}{ Smoking status } \\
\hline Smoker $(-)$ & 1.00 & & & \\
\hline Smoker $(+)$ & $1.64(0.91-2.94)$ & 0.098 & & \\
\hline Pack-years of cigarette smoking & & & $1.01(0.99-1.02)$ & 0.109 \\
\hline \multicolumn{5}{|l|}{ Periodontitis $(+)$} \\
\hline \multicolumn{5}{|l|}{ Smoking status } \\
\hline Smoker $(-)$ & 1.00 & & & \\
\hline Smoker $(+)$ & $2.45(1.37-4.37)$ & 0.002 & & \\
\hline Pack-years of cigarette smoking & & & $1.02(1.01-1.03)$ & $<0.001$ \\
\hline
\end{tabular}

COPD when smoking was included in the same model. Among prior studies reporting an association between periodontitis and COPD (7-10,21), Chung et al. (21) recently reported that COPD risk was higher for Korean men with periodontitis, as defined by a CPI of 3 or 4 , than for those with a CPI of 0 , after adjusting for smoking and other potential confounders. When we used the same definition of periodontal health to analyze our data (with a CPI of 0 as the reference category), periodontitis was not significantly associated with COPD. However, we were unable to analyze separately men with a CPI of 3 or 4 , as only 27 of the present participants had a CPI of 4. Thus, periodontitis was defined as a CPI $\geq 3$ (OR 1.35; 95\% CI 0.77-2.37, data not shown). The assessment of and diagnostic criteria for periodontitis and COPD were the same in both studies, so the contrasting results might 
Table 4 Odds ratios (ORs) for the combined association of periodontitis and smoking with COPD

\begin{tabular}{lcc}
\hline & Adjusted OR (95\% CI) & $P$ value \\
\hline Periodontitis and smoking status & & \\
Periodontitis $(-)$, smoker $(-)$ & 1.00 & 0.932 \\
Periodontitis $(+)$, smoker $(-)$ & $0.97(0.49-1.91)$ & 0.078 \\
Periodontitis $(-)$, smoker $(+)$ & $1.68(0.94-2.99)$ & 0.003 \\
Periodontitis $(+)$, smoker $(+)$ & $2.27(1.31-3.92)$ & \\
\hline ORs are adjusted for age, number of present teeth, body mass index, alcohol intake, occupation, \\
hypertension and diabetes. COPD, chronic obstructive pulmonary disease; OR, odds ratio; CI, \\
confidence interval.
\end{tabular}

be attributable to differences in study setting. The Korean men were community residents, whereas our participants were men receiving optional health check-ups. However, our findings are consistent with those of a study (17) that analyzed data from the Third National Health and Nutritional Examination Survey and found that periodontal disease was not associated with COPD, after adjusting for smoking and other potential confounders. A possible explanation for the absence of a significant association between periodontitis and COPD is that periodontitis is not as strongly associated with COPD as it is with smoking. Moreover, periodontitis alone may not increase COPD risk.

COPD risk was higher among smokers with periodontitis, which supports the hypothesis that periodontitis modifies the association between smoking and COPD. This relationship may be attributable to an inflammatory response. COPD is characterized by chronic airway inflammation, which is often caused by long-term smoking (22). Smoking is believed to elicit an inflammatory response resulting in increased release of tissue destructive substances, including proinflammatory cytokines (23). In addition, elevated systemic inflammation is associated with COPD exacerbation (24). Several cross-sectional studies reported that systemic inflammation was more severe among patients with periodontitis than among healthy individuals $(25,26)$, which suggests that periodontitis is linked to systemic inflammation. In smokers with COPD, periodontitis may be associated with even greater systemic inflammation. It is possible, therefore, that periodontitis strengthens the association between smoking and COPD through an inflammatory response. In view of this, coexistence of periodontitis and smoking deserves more attention as a potential risk factor for COPD.

This study has several limitations. First, the crosssectional study design makes it difficult to identify temporal relationships. Longitudinal studies are required in order to gain a clearer understanding of the associations between periodontitis, smoking, and COPD. Second, our findings may not be representative of the general population, as the participants underwent voluntary paid check-ups and are thus likely to be healthier than the general population. The COPD prevalence of $10.2 \%$ for men is considerably lower than the $16.4 \%$ of Japanese adults with COPD in a study by Fukuchi (3). This difference may be due to the fact that Fukuchi's study subjects were demographically representative of the general Japanese population (3). Another potential reason is that the prevalences of $15.4 \%$ and $15.6 \%$, for former and current smokers respectively (3), are higher than the $11.5 \%$ prevalence for former/current smokers in our study. Our sampling method restricts generalization of our results to the wider Japanese male population. Third, we used CPI to assess periodontal status, so periodontal condition was not comprehensively evaluated. Moreover, it is likely that mild periodontitis was included in this study, because our definition of periodontitis was the presence of at least one sextant with a pocket depth $\geq 4 \mathrm{~mm}$. Nevertheless, periodontitis, as defined by our criteria, is associated with systemic inflammation. Moreover, a previous study found that subjects with periodontitis, as defined by the same criteria, had higher C-reactive protein levels than did subjects without periodontitis (27). We observed similar results: C-reactive protein concentration was 0.13 $\pm 0.26 \mathrm{mg} / \mathrm{dL}$ in men with periodontitis and $0.10 \pm 0.21$ $\mathrm{mg} / \mathrm{dL}$ in men without periodontitis $(P=0.002$; data not shown).

Despite these limitations, our results indicate that the association between smoking and COPD is stronger in men with periodontitis than in those without periodontitis. The present results highlight the importance of maintaining good periodontal health and the possible benefits of stopping or reducing smoking for decreasing COPD risk and thus improving patient quality of life.

\section{Acknowledgments}

This study was supported by JSPS KAKENHI Grant Numbers JP16H05850 and JP26861832. 


\section{Conflict of interest}

The authors report no conflict of interest.

\section{References}

1. Halbert RJ, Natoli JL, Gano A, Badamgarav E, Buist AS, Mannino DM (2006) Global burden of COPD: systematic review and meta-analysis. Eur Respir J 28, 523-532.

2. Buist AS, McBurnie MA, Vollmer WM, Gillespie S, Burney P, Mannino DM et al. (2007) International variation in the prevalence of COPD (the BOLD Study): a population-based prevalence study. Lancet 370, 741-750.

3. Fukuchi Y, Nishimura M, Ichinose M, Adachi M, Nagai A, Kuriyama $\mathrm{T}$ et al. (2004) COPD in Japan: the Nippon COPD epidemiology study. Respirology 9, 458-465.

4. Pauwels RA, Buist AS, Calverley PM, Jenkins CR, Hurd SS (2001) Global strategy for the diagnosis, management, and prevention of chronic obstructive pulmonary disease. NHLBI/WHO Global Initiative for Chronic Obstructive Lung Disease (GOLD) Workshop summary. Am J Respir Crit Care Med 163, 1256-1276.

5. Mathers CD, Loncar D (2006) Projections of global mortality and burden of disease from 2002 to 2030. PLoS Med 3, e442.

6. Mannino DM, Braman S (2007) The epidemiology and economics of chronic obstructive pulmonary disease. Proc Am Thorac Soc 4, 502-506.

7. Garcia RI, Nunn ME, Vokonas PS (2001) Epidemiologic associations between periodontal disease and chronic obstructive pulmonary disease. Ann Periodontol 6, 71-77.

8. Scannapieco FA, Ho AW (2001) Potential associations between chronic respiratory disease and periodontal disease: analysis of National Health and Nutrition Examination Survey III. J Periodontol 72, 50-56.

9. Azarpazhooh A, Leake JL (2006) Systematic review of the association between respiratory diseases and oral health. $\mathrm{J}$ Periodontol 77, 1465-1482.

10. Zeng XT, Tu ML, Liu DY, Zheng D, Zhang J, Leng W (2012) Periodontal disease and risk of chronic obstructive pulmonary disease: a meta-analysis of observational studies. PLoS One 7, e46508.

11. Tonetti MS (1998) Cigarette smoking and periodontal diseases: etiology and management of disease. Ann Periodontol 3, 88-101.

12. Calsina G, Ramon JM, Echeverria JJ (2002) Effects of smoking on periodontal tissues. J Clin Periodontol 29, 771-776.

13. Ojima M, Hanioka T, Tanaka K, Inoshita E, Aoyama H (2006) Relationship between smoking status and periodontal conditions: findings from national databases in Japan. J Periodontal Res 41, 573-579.

14. Moimaz SA, Zina LG, Saliba O, Garbin CA (2009) Smoking and periodontal disease: clinical evidence for an association. Oral Health Prev Dent 7, 369-376.

15. Geijer RM, Sachs AP, Verheij TJ, Salomé PL, Lammers JW, Hoes AW (2006) Incidence and determinants of moderate COPD (GOLD II) in male smokers aged 40-65 years: 5-year follow up. Br J Gen Pract 56, 656-661.

16. Lokke A, Lange P, Scharling H, Fabricius P, Vestbo J (2006) Developing COPD: a 25 year follow up study of the general population. Thorax 61, 935-939.

17. Hyman JJ, Reid BC (2004) Cigarette smoking, periodontal disease: and chronic obstructive pulmonary disease. J Periodontol 75, 9-15.

18. Bergström J, Cederlund K, Dahlén B, Lantz AS, Skedinger M, Palmberg L et al. (2013) Dental health in smokers with and without COPD. PLoS One 8, e59492.

19. Holtfreter B, Richter S, Kocher T, Dorr M, Volzke H, Ittermann $\mathrm{T}$ et al. (2013) Periodontitis is related to lung volumes and airflow limitation: a cross-sectional study. Eur Respir J 42, 1524-1535.

20. Ainamo J, Barmes D, Beagrie G, Cutress T, Martin J, Sardo-Infirri J (1982) Development of the World Health Organization (WHO) community periodontal index of treatment needs (CPITN). Int Dent J 32, 281-291.

21. Chung JH, Hwang HJ, Kim SH, Kim TH (2016) Associations between periodontitis and chronic obstructive pulmonary disease: the 2010 to 2012 Korean national health and nutrition examination survey. J Periodontol 87, 864-871.

22. Tanni SE, Pelegrino NR, Angeleli AY, Correa C, Godoy I (2010) Smoking status and tumor necrosis factor-alpha mediated systemic inflammation in COPD patients. J Inflamm (Lond) 7, 29.

23. Johannsen A, Susin C, Gustafsson A (2014) Smoking and inflammation: evidence for a synergistic role in chronic disease. Periodontol 2000 64, 111-126.

24. Groenewegen KH, Postma DS, Hop WC, Wielders PL, Schlosser NJ, Wouters EF (2008) Increased systemic inflammation is a risk factor for COPD exacerbations. Chest 133, 350-357.

25. Fredriksson MI, Figueredo CM, Gustafsson A, Bergstrom KG, Asman BE (1999) Effect of periodontitis and smoking on blood leukocytes and acute-phase proteins. J Periodontol 70, 1355-1360.

26. Noack B, Genco RJ, Trevisan M, Grossi S, Zambon JJ, De Nardin E (2001) Periodontal infections contribute to elevated systemic C-reactive protein level. J Periodontol 72, 12211227.

27. Takami Y, Nakagaki H, Morita I, Tsuboi S, Takami S, Suzuki $\mathrm{N}$ et al. (2003) Blood test values and Community Periodontal Index scores in medical checkup recipients. J Periodontol 74, 1778-1784. 